\title{
Building Evaluation Culture and Capacity in a Community-Level Program: Lessons Learned from Evaluating Youth Futures
}

\section{Vivien Runnels, Caroline Andrew, and Jennifer Rae \\ University of Ottawa}

\begin{abstract}
Youth Futures is a complex program supported by a local partnership aimed at increasing access to post-secondary education among youth from lower-income family backgrounds. Although program stakeholders have recognized the importance of evaluation since the program's inception, embedding an evaluative culture and building capacity for evaluation practice in the context of this partnership-led program has been challenging. We describe our experiences and the lessons that have been learned about generating and sustaining interest in evaluation among a diverse group of stakeholders. The article proposes some recommendations for others who endeavour to conduct evaluation work in community contexts.
\end{abstract}

Keywords: evaluation capacity building, evaluation practice, evaluative culture, implementation evaluation, partnership

Résumé : Avenir Jeunesse est un programme complexe, appuyé par un partenariat local, qui vise à accroître l'accès aux études postsecondaires pour les jeunes venant de milieux marginalisés. Bien que les parties prenantes aient reconnu l'importance de lévaluation dès la création du programme, intégrer une culture de l'évaluation et construire la capacité pour une pratique de l'évaluation dans ce programme mené en partenariat a présenté des défis. Nous décrivons nos expériences et des leçons qui ont été tirées quant aux façons de construire la capacité évaluative et de générer et maintenir un intérêt pour lévaluation parmi un groupe divers de partenaires. L'article propose des recommandations pour d'autres qui cherchent à faire du travail dévaluation en contexte communautaire.

Mots clés : lévaluation du renforcement des capacités, la pratique en évaluation, une culture évaluative, lévaluation de la mise en ouvre, le partenariat

Youth Futures is a program aimed at increasing post-secondary education (PSE) engagement targeted at youth from lower-income family backgrounds. Every year over the course of seven months, the program provides high-school youth

Corresponding author: Vivien Runnels, Centre for Research on Educational and Community Services, Faculty of Social Sciences, University of Ottawa, 136 Jean Jacques Lussier, Ottawa,

ON, K1N 6N5; email: vrunnels@uottawa.ca

(C) 2017 Canadian Journal of Program Evaluation / La Revue canadienne d'évaluation de programme 32.1 (Spring / printemps), 122-130 doi: 10.3138/cjpe.30975 
with leadership training, exposure to post-secondary institutions, mentoring, and paid summer employment. The program is supported by a partnership comprised of a municipality, five post-secondary institutions, and several community-based organizations in Ottawa, Ontario. These stakeholders are interested in making the best use of the partnership's resources, skills, and knowledge to bring about the best possible outcomes for the participants of Youth Futures. The evaluation of Youth Futures is a means to that end and has gradually emerged to become a priority for the partnership. In this Evaluation Practice Note, we describe the history and processes through which Youth Futures has come to acquire elements of an evaluative culture from our perspective as stakeholders in Youth Futures.

In an evaluative culture, organization members-particularly senior leadersbelieve in the value of evaluation and demonstrate this belief by talking about evaluation, asking evaluative types of questions, gathering data to support decision making, and regularly initiating and conducting formal evaluation work to improve performance and accomplish organizational goals (Mayne, 2010; Preskill \& Boyle, 2008). Evaluation capacity building (ECB) is a process through which an organization's ability to do and use evaluation becomes enhanced (Labin, Duffy, Meyers, Wandersman, \& Lesesne, 2012). ECB may employ various teaching and learning strategies to help organizations learn about evaluation, with the goal of instituting sustainable, useful, quality evaluation practice (Preskill \& Boyle, 2008). As a result, individual members of an organization have the necessary attitudes (affect), knowledge, and skills (behaviours), and the organization itself has the necessary processes, policies, practices, leadership, and resources for evaluation (Cousins, Goh, Clark, \& Lee, 2004; Labin, Duffy, Meyers, Wandersman, \& Lesesne; Preskill \& Boyle, 2008). Capacity to carry out evaluation is integrated into the organizational culture, and evaluative culture becomes a norm, informing and shaping evaluation practice in an organization. Two types of ECB have been identified in the literature: direct ECB and indirect ECB (Cousins, Goh, Clark, \& Lee, 2004; Cousins, Goh, Elliott, \& Bourgeois, 2014). Direct ECB involves planned, deliberate activities that may (or may not) occur within the scope of an actual evaluation project. In contrast, indirect ECB is not necessarily intentional, but accomplished through process use and learning (Patton, 1997).

It is important that ECB theory and research be closely informed by practice (Preskill, 2014; Suarez-Balcazar \& Taylor-Ritzler, 2014). To this end, we believe that it is useful to examine the case study of the Youth Futures program, which has developed elements of a strong evaluative culture through a process in practice that is illustrative of indirect ECB. This Evaluation Practice Note is presented from the perspective of two Youth Futures stakeholders (one of whom is a Youth Futures leader [CA]) and the other of whom is a researcher [VR]) and offers insight into some opportunities and challenges that organizational leaders may encounter when trying to pursue the practice of evaluation. 


\section{REFLECTING ON THE EVOLUTION OF EVALUATION IN YOUTH FUTURES}

\section{Early years: Program building and partnership development}

The evaluation of the Youth Futures program, which has now been in operation for 10 years, was not a priority in its early iterations. This was due to the way the program was funded and developed. Youth Futures was initiated when two professors at the University of Ottawa received an unexpected donation from an anonymous funder with an instruction to implement a program within a very short period to increase PSE engagement for youth from lower-income family backgrounds. Since the program was implemented within days, the founders did not have time to plan for evaluation, nor was there any incentive to do this as the funder had already hired an external evaluator. ${ }^{1}$ In its second year of operation, the funding source changed, and the fledgling program received financial support from a provincial government fund for the recruitment and retention of "first generation" students in PSE. For a second time, the provision of funds was not contingent on any kind of program evaluation.

Another reason that evaluation did not come to be prioritized in the early years had to do with the demands of developing relationships and the partnership necessary for implementing a complex community-based program. Youth Futures' partners are from different sectors, agencies, and organizations, and each partner makes a unique contribution to a given aspect of the program. Therefore, the program's implementation is highly dependent on inter-organizational relationships and their coordination. The development of the partnership and the establishment of governing structures was a time-consuming process that required a lot of personal contact and relationship building. Further, developing and enhancing the program content and increasing the number of participants took the young partnership all of the time and resources it could muster. Implementing the program was especially demanding considering that the partners' involvement in Youth Futures was in addition to the heavy workloads that they already were spending in their jobs. Thus, evaluation took a back seat to relationship building, establishing the partnership's governance structure, and implementing the program.

On reflection, the lack of evaluation activity in the program's early years is not surprising. Interest in evaluation is not usually inherent in an organization's context-it is "triggered" by some internal or external demand or condition that incentivizes evaluation (Labin, Duffy, Meyers, Wandersman, \& Lesesne; Preskill \& Boyle, 2008; Stewart, 2014). In the early years, motivation and incentives to conduct evaluation of Youth Futures had not yet been triggered, and evaluation activities could not yet be balanced with other work demands. However, this was to change.

\section{Middle stages: The need for evaluation emerges}

As Youth Futures continued into its third year of operation, the program was maturing. Its partnership became established and stable, governance structures 
were solidified (the Coordinators' Table, which was the committee of community partners implementing the program and the Champions' Table, which was the "higher" level committee that dealt with the strategic directions of Youth Futures), and the program formalized. Partners were able to devote attention to matters beyond the urgent immediate operational issues that had previously dominated their time, and they expressed curiosity about the program and how, and how well, it was working. Partners, especially members of the Coordinators' Table, wanted to document current program activities, determine which aspects of the program were important to meeting program goals, and gauge participant satisfaction with the program.

At the same time that these evaluative-type questions were spontaneously arising within the partnership, serendipitously, an evaluation opportunity presented itself. A research network, the Population Health Improvement Research Network (PHIRN), based at the Institute of Population Health at the University of Ottawa and funded by the Ministry of Health and Long-Term Care of Ontario, ${ }^{2}$ was conducting research based on requests generated by Ontario governments, ministries, and community health agencies. The population health focus of this network's research was well suited for evaluating an intervention such as Youth Futures, which is aimed at high-school students in Ottawa coming from "at risk" backgrounds for social and health inequalities. Youth Futures submitted a successful application to the PHIRN to carry out an implementation evaluation of Youth Futures.

The trigger for the collaboration between Youth Futures and the PHIRN that resulted in the implementation evaluation was a simple conversation between two colleagues-informal and not explicitly planned or deliberate (Runnels, 2013). Collaboration has been identified as a key element of ECB. Through collaborative partnerships and relationships, organizations can gain access to consultation and advice on evaluation and leverage evaluation resources and expertise including financial resources (General Accounting Office, 2003; Preskill \& Boyle, 2008).

\section{An introduction to evaluation}

The concept of process use in ECB suggests that evaluation capacity can be built indirectly as a result of stakeholders' participation in evaluation activities (Cousins, Goh, Clark, \& Lee, 2004). This was certainly the case for the Youth Futures program with stakeholders participating in various elements and stages of the implementation evaluation. For example, an Evaluation Steering Committee was struck to work with a PHIRN researcher (VR) conducting the evaluation. Establishing an organizational structure like a committee to support and facilitate evaluation is a documented ECB strategy (Volkov \& King, 2007). The Evaluation Steering Committee was open to any interested program stakeholders and was ultimately comprised of the two program founders, two program co-ordinators (past and present), two students (including one who had worked as a Youth Futures mentor) and two evaluation advisors who were University of Ottawa colleagues of the founders. (The involvement of the latter has developed into a 
long-term advisory relationship with Youth Futures' research and evaluation activities). The participation of the founders on the Evaluation Steering Committee is also important to note, given the evidence suggesting that leaders who demonstrate a clear commitment to evaluation positively influence the integration of an evaluative culture (Cousins, Goh, Clark, \& Lee, 2004; Mayne, 2010; Stewart, 2014; Volkov \& King, 2007). The members of the Evaluation Steering Committee were familiar with the program and used this familiarity to give ongoing guidance to the evaluator, ensure the relevance of the evaluation questions and methods, and review the draft evaluation report before distribution to the program stakeholders.

In addition to the formation of the Evaluation Steering Committee, the evaluation process inspired for the first time the development of a Youth Futures program logic model (PLM) in which the program's mission, vision, and values were formalized and documented. The development of the PLM became particularly important for unifying the Coordinators' Table around a common cause and set of understandings. Second, key informant interviews carried out to collect data for the evaluation, encouraged program partners to reflect on Youth Futures and their own role in the program and partnership. These interviews also provided evidence of the partners' clear sense of ownership and dedication to the program, trust between partners, and recognition of each partner's participation and contributions to Youth Futures. These findings were important to establish since a lack of trust can undermine programs and partnerships (Runnels \& Andrew, 2013). In addition the evaluation led to the identification of program gaps. For example, improvements to the program's record-keeping practices were recommended after gaps in program documentation were identified. Finally, the implementation evaluation report itself, which provided several recommendations for program change (several of which were subsequently implemented), served as an important reference document.

Overall, the implementation evaluation was an important first step for Youth Futures. The development of an evaluative culture has previously been described as a "reinforcing cycle," whereby evaluation provides useful information and experiences to stakeholders, who then come to support future evaluation efforts (General Accounting Office, 2003). This evaluation was a positive experience that demonstrated how useful evaluation can be, inspiring stakeholders to realize that evaluation-and more of it-could be beneficial for making improvements to the program. The Evaluation Steering Committee expanded its membership to include more program stakeholders, including the researcher who had conducted the implementation evaluation. Commencing with the PHIRN collaboration, Youth Futures has since extended and expanded its relationship with the University of Ottawa, enabling program stakeholders to solicit resources and evaluation advice from academics with expertise in evaluation and to build the evaluation capacity of the partnership.

\section{Pursuing a partnership development evaluation}

As Youth Futures continued to grow and show success through its participants' achievements, there was a sense among stakeholders that the program depended 
on a "special" kind of partnership. There were questions about how the partnership worked and whether it could ever be replicated elsewhere if Youth Futures was to expand to other sites. These questions prompted the Evaluation Steering Committee to apply for a Social Sciences and Humanities Research Council Partnership Development Grant to evaluate the partnership's development. Developing proposals and persistently applying for grant funding is recommended, especially for non-profit organizations, as a way of garnering explicit, dedicated funding for program evaluation activities (Hoole \& Patterson, 2008; Preskill \& Boyle, 2008; Stewart, 2014).

The research proposal was successful, meaning that Youth Futures had access to evaluation-dedicated resources for three years. There were two main components of the Youth Futures partnership development grant. Part of the funding was allocated toward engaging a doctoral student (JR) whose doctoral thesis research was a pilot outcome evaluation of the Youth Futures' program. Recruiting a graduate student to carry out the evaluation was a mutually beneficial arrangement to the Youth Futures' program and partnership and to the student. Both partnership and student have learned about designing and conducting an outcome evaluation, and this process use of evaluation has continued to stimulate learning about evaluation, building the partnership's interest and capacity for evaluation. For example, the evaluation process has provoked critical conversations around the target population for Youth Futures, how to ensure fair and equitable recruitment of program participants, and how to establish more explicit acceptance criteria for potential participants.

The second component of the grant was the evaluation of the partnership development itself, which is still underway at the time of writing. An external evaluation consultant was engaged to facilitate the evaluation with the Coordinators' Table. This group actively engaged in the partnership development evaluation process, was responsible for generating the evaluation questions, and participated extensively in the discussion around design and implementation of the evaluation. This high level of involvement and participation in evaluation is considered a powerful predictor of cultural change in an organization, fostering interest, motivation, and buy in, as well as increased evaluation knowledge and skills (Stewart, 2014).

The grant award itself was celebrated at an all-stakeholder research and evaluation meeting, which provided everyone with the opportunity to network, talk about evaluation, and reflect on next steps. This meeting was so well received that it was instituted as an annual event. Purposeful opportunities to interact, socialize, and celebrate achievements are an important way to embed evaluation into an organization's culture (Preskill \& Boyle, 2008; Volkov \& King, 2007). Regular meetings with Youth Futures' stakeholders have helped to ensure that evaluation is understood and appreciated, encouraging stakeholders to continue their engagement with evaluation and make use of evaluation results.

\section{The future: Planning ongoing evaluation work}

The partners of Youth Futures who provide political, in kind, and financial support for the program have grown increasingly interested in demonstrating the program participants' education and employment outcomes. Short-term personal change 
in the youth over the course of the program has been observed, but outcomes have yet to be captured through the systematic data collection of an outcome evaluation over a period of years. While the partners are accountable to Youth Futures, they are also accountable to their own organizations to demonstrate that the program is achieving its mandate. Other parties have also expressed interest in the Youth Futures partnership model, and they have posed questions about the sustainability of the program and its transferability to other contexts. In response to these requirements and interests, a grant proposal for an outcome evaluation of Youth Futures is in development, making use of the lessons learned from the aforementioned pilot outcome evaluation, in a context in which evaluation is now embedded and understood.

\section{LEARNINGS FOR EVALUATION PRACTICE}

In summary, we suggest that knowledge of our experiences can be transferred to both evaluation practitioners and program stakeholders in other contexts and used to develop a more intentional approach to evaluation culture, ECB, and evaluation practice in contrast to the Youth Futures experience. For program stakeholders, building an evaluative culture and ECB requires resources, including time, money, skills, and evaluation knowledge. Acquiring resources, however, means stakeholders need to look outside the program box, leveraging opportunities and oftentimes developing collaborations or partnerships. With universities as partners, supervised graduate students may be available to provide evaluation knowledge and carry out the work in exchange for evaluation experience, helping them to complete courses, participate in on-site internships, and take part in reporting and publication of the results.

Developing funding proposals for research and evaluation takes a great deal of partnership time and effort. These proposals present a risk in terms of loss of investment if they are not successful, but even unsuccessful proposals can encourage process use, with partners learning, expanding their knowledge, and nurturing an evaluative culture. Partnership members can also furnish resources for evaluation. Individual partners from different sectors can provide skills and knowledge as well as creating opportunities for funding and/or garnering support from other bodies (for example, academic partners can directly apply to funding agencies and internal competitions for research funds as Youth Futures has done).

For evaluation practitioners, we think our most helpful learning has been to recognize that certain concrete steps, and the institution of evaluation-focused structures, have contributed to the formation of an evaluative culture and developed the partnership's capacity for evaluation. In the case of Youth Futures, an Evaluation Steering Committee and the annual all-stakeholder research and evaluation meetings have been critical in this development. Having an external evaluator work on the partnership development evaluation has also brought fresh knowledge of the process and purpose of evaluation, allowing partners to make 
cognitive links to the value of program evaluation. We have found it difficult in practice to separate the genesis of evaluative culture and to build evaluation capacity. In our experience, they have gone hand in hand and encompass direct and indirect ECB. Process use and learning about evaluation have been more prominent in our partnership in building capacity and an evaluative culture than the use of findings delivered to the partnership from an evaluation report. We think this is in part because the emergence of findings takes place in the evaluation process and are made use of as they arise. Despite a slow start in adopting evaluation, the subsequent development of an evaluative culture and the expansion of the capacity to carry out evaluation have reinforced the stakeholders' commitment to furthering evaluation work in its planned outcome evaluation.

To conclude, Youth Futures was slow to prioritize and take up evaluation; however, over time, sharing learning and seizing opportunities have encouraged the integration and institutionalization of evaluation into the program and the partnership. Despite the challenges of operational demands, a diverse partnership, and limited financial resources, the stakeholders of Youth Futures and the partnership as a whole now demonstrate a commitment to evaluation to inform decision making and accomplish program goals.

\section{NOTES}

1 In this case, the evaluation findings were, in fact, only ever shared with the funder, not with the program, so were therefore of no use for program improvement.

2 The Population Health Improvement Research Network based in Ottawa was "a provincewide network linking population health researchers and community partners in order to improve the health of Ontarians and the sustainability of the health care system. We were created with funds from the Ministry of Health and Long Term Care to support high-quality applied population health research that addresses complex issues that affect health and health equity using a collaborative approach and to promote the production and dissemination of new knowledge, best practices and policies." See Population Health Improvement Research Network (Ivy Lynn Bourgeault, Scientific Director), http://www.rrasp-phirn.ca/.

\section{REFERENCES}

Cousins, B., Goh, S., Clark, S., \& Lee, L. (2004). Integrating evaluative inquiry into the organizational culture: a review and synthesis of the knowledge base. Canadian Journal of Program Evaluation, 19(2), 99-141.

Cousins, B., Goh, S., Elliott, C., \& Bourgeois, I. (2014). Framing the capacity to do and use evaluation. New Directions for Evaluation, 141, 7-23. https://doi.org/10.1002/ev.20076

General Accounting Office (2003). An evaluation culture and collaborative partnerships help build agency capacity: Program evaluation: A report to Congressional Committees. Washington, DC. http://www.gao.gov/new.items/d03454.pdf

Hoole, E., \& Patterson, T. E. (2008). Voices from the field: Evaluation as part of a learning culture. New Directions for Evaluation, 119, 93-113. https://doi.org/10.1002/ev.270 
Labin, S. N., Duffy, J. L., Meyers, D. C., Wandersman, A., \& Lesesne, C. A. (2012). A research synthesis of the evaluation capacity building literature. American Journal of Program Evaluation, 33(3), 307-338.

Mayne, J. (2010). Building an evaluative culture: The key to effective evaluation and results management. Canadian Journal of Program Evaluation, 24(2), 1-30.

Patton, Q. M. (1997). Utilization focused evaluation: The new century text (3rd ed.). London: Sage Publications.

Preskill, H. (2014). Now for the hard stuff: Next steps in ECB research and practice. American Journal of Evaluation, 35(1), 116-119. https://doi.org/10.1177/1098214013499439

Preskill, H., \& Boyle, S. (2008). A multidisciplinary model of evaluation capacity building. American Journal of Evaluation, 29(4), 443-459. https://doi. org/10.1177/1098214008324182

Runnels, V. (2013). Youth Futures/L’Avenir Jeunesse: A process evaluation. Ottawa: Population Health Improvement Research Network. http://rraspphirn.ca/images/stories/ docs/workingpaperseries/Download_2340_KB.pdf

Runnels, V., \& Andrew, C. (2013). Community-based research decision-making: Experiences and factors affecting participation. Gateways: International Journal of Community Research and Engagement, 6(1), 22-37. https://doi.org/10.5130/ijcre.v6i1.3257

Stewart, J.M. (2014). Developing a culture of evaluation and research. CFCA Paper no. 28. Sydney: Australian Institute of Family Studies.

Suarez-Balcazar, Y., \& Taylor-Ritzler, T. (2014). Moving from science to practice in evaluation capacity building. American Journal of Program Evaluation, 35(1), 95-99. https:// doi.org/10.1177/1098214013499440

Volkov, B., \& King, J. (2007). A checklist for building organizational evaluation capacity. http://www.wmich.edu/sites/default/files/attachments/u350/2014/organiziationevalcapacity.pdf

\section{AUTHOR INFORMATION}

Vivien Runnels works with the Centre for Research on Educational and Community Services at the Faculty of Social Sciences and is a senior researcher with the Globalization and Health Equity Research Unit in the School for Epidemiology, Public Health and Preventive Medicine in the Faculty of Medicine at the University of Ottawa. She has worked on studies of global health diplomacy; health human resources and migration; medical tourism and out-ofcountry care; population health interventions, sex and gender analysis, program evaluation, qualitative research, and community-based research and has also published in these areas.

Caroline Andrew is the director of the Centre on Governance in the Faculty of Social Sciences at the University of Ottawa. Her research centres on the study of partnerships between community-based equity-seeking groups (particularly around recent immigrants and women and girls in all their diversity) and municipal governments.

Jennifer Rae is a PhD candidate in experimental psychology at the Centre for Research on Educational and Community Services at the University of Ottawa. Her research interests include community mental health and homelessness and program evaluation of community-based interventions for marginalized populations. 